\title{
1 Progressive maturation of the root apical meristem in Arabidopsis thaliana lateral roots
}

3

4 Béatrice Berthet, Lotte Bald, Marion Louveaux and Alexis Maizel ${ }^{\star}$

5

6 Center for Organismal Studies (COS), University of Heidelberg, Im Neuenheimer Feld 230,

769120 Heidelberg, Germany.

8

9 * to whom correspondence should be addressed: alexis.maizel@cos.uni-heidelberg.de

13 Emails \& ORCID IDs

14 Béatrice Berthet beatrice.berthet@hotmail.fr 0000-0003-2651-4854

15 Lotte Bald lotte.bald@cos.uni-heidelberg.de 0000-0002-9471-2716

16 Marion Louveaux marion.louveaux@gmail.com 0000-0002-1794-3748

17 Alexis Maizel alexis.maizel@cos.uni-heidelberg.de 0000-0001-6843-1059 18

19 Number of figures: 4

20 Number of tables: 0

21 Number of supplemental figures: 4

22 Running title: Lateral root apical meristem maturation in Arabidopsis 


\section{Highlight}

24 Analyze of the ontogeny of the quiescent center during lateral root ontogeny reveal its late 25 formation and supports that its emergence results from the establishment of two diverging growth 26 axis.

\section{Abstract}

29 Meristems are stem cells niches that support the formation of all plant organs and are either set 30 during embryogenesis and maintained throughout the plant life or specified de novo, post31 embryonically. The embryo-derived root apical meristem is organized around a group of 32 infrequently dividing cells, the quiescent centre, that maintains the stem cells, organizes growth 33 along two axes and owing to its resistance to 3ic stress can replace damaged stem cells. In most 34 cases, lateral roots post-embryonically branch off the primary and establish a new root meristem 35 which organization is identical to the primary root one. The cellular and molecular processes 36 underpinning the emergence of new stem cell niches are not well known. Here, we characterize 37 the de novo establishment of the root apical meristem in lateral roots. While the position of the 38 new stem cell niche is set early during morphogenesis, its cellular layout, unique gene expression 39 profile and mitotic quiescence are only acquired after emergence concomitant to the establishment 40 of two diverging growth axis. Our results show that the intertwined attributes of the mature root 41 stem cell niche are progressively acquired during lateral root formation, and support a model in 42 which the position of the stem cell niche emerges from the establishment of diverging growth axis. 43

\section{Keywords}

45 apical meristem; Arabidopsis thaliana; lateral root; maturation; quiescent centre; root; stem cells ; 


\section{Introduction}

47 Above and below ground axial growth of plants is supported by primary meristems that are established during embryogenesis activated upon germination (Greb and Lohmann, 2016; ten Hove et al., 2015). Post embryonically, secondary meristems are established and allow branching and radial growth (Greb and Lohmann, 2016). These secondary meristems have a different ontogeny from their embryonic counterparts, but their organization and function is very comparable to the primary ones. They are thus very useful for elucidating the mostly unknown cellular and

53 molecular processes governing the generation of new meristems (Greb and Lohmann, 2016).

54 Lateral root (LR) branching from the primary or other root is an example of an organ which growth 55 is supported by a secondary meristem (Motte et al., 2019). In Arabidopsis thaliana (Arabidopsis), 56 LR initiate deep within the primary root, where a few cells of the pericycle adjacent to the xylem 57 radially expand and divide asymmetrically in response to local accumulation of the phytohormone auxin. These cells further grow, alternate rounds of anticlinal and periclinal divisions and form a dome shaped LR primordium (LRP) with a regular cellular layout which allows classification of its development in seven developmental stages (stage I to stage VII) (Malamy and Benfey, 1997; von Wangenheim et al., 2016). Ultimately, the new LR forms a new meristem with a cellular and functional organization quasi identical to the one of the primary root meristem (Tian et al., 2014b).

64 Meristems contain stem cells, also called initials, which activity is maintained by a group of rarely or non-dividing cells forming the organising centre in the shoot and the quiescent centre (QC) in the root (Dubrovsky and Ivanov, 2021). In Arabidopsis, the cellular organization of the root apical meristem (RAM) is simple and stereotyped with the central stem cells surrounding the QC. The stem cells, also called initials, provide, through asymmetric divisions, the progenitors for the root tissues and the root cap (Dolan et al., 1993). The concept of QC was formulated by F. A. L. Clowes

70 (Clowes, 1956) and originally referred to both the organizer and the initials (Dubrovsky and Ivanov, 71 2021). A more restrictive definition of the $Q C$, that only refers to the four to six apically located very

72 slowly dividing cells was later adopted in Arabidopsis (Dolan et al., 1993; Dubrovsky and Ivanov,

73 2021). Here, we will use this latter definition for the QC. In addition to its low mitotic activity

74 (Clowes, 1954; Clowes, 1956), the Arabidopsis QC is defined by additional features. First, it acts

75 as an organiser that maintains the stem cell identity of cells in its direct contact (van den Berg et 76 al., 1995; van den Berg et al., 1997). Second, it is characterized by abundance of auxin, an 77 oxidizing environment and enrichment for expression of many genes and markers (Brumos et al., 78 2018; Haecker et al., 2004; Jiang et al., 2003; Nawy et al., 2005; Petersson et al., 2009; Sabatini 79 et al., 1999). Third, the QC serves as a reservoir of cells to allow the meristem to recover from 80 wounding or severe genotoxic damage by replacing compromised or missing cells (Clowes, 1959; 81 Efroni et al., 2016; Fulcher and Sablowski, 2009; Tsugeki and Fedoroff, 1999). Thus, the QC 
82

defines through its specific central location a microenvironment, akin to a niche, that maintains the cellular organization of the meristem (Dubrovsky and Ivanov, 2021). The embryonic origin of the QC in Arabidopsis can be traced back to the late globular stage and the division of the hypophysis (Dolan et al., 1993; Scheres et al., 1994; ten Hove et al., 2015). Studies in maize indicate that all cells of the embryonic root proliferate and that quiescence of the QC is only established late during embryogenesis (Clowes, 1978; Dubrovsky and Ivanov, 2021).

8

In LR, seminal works hint at a late formation of the QC in the water cabbage Pistia, the water hyacinth Eichhornia, bean (Vicia faba), mallow (Malva sylvestris) and Maize (Byrne, 1973; Clowes, 1958; Clowes, 1978; Macleod, 1977). In Arabidopsis, it was proposed that the formation of the RAM in lateral root only occurs after an initial early morphogenesis phase (up to stage IV/V) (Laskowski et al., 1995). Similarly, RAM formation in adventitious roots has been reported to take place late (Della Rovere et al., 2013). Using reporters for QC markers, Goh et al. traced back the origin of QC cells to the stage II LRP cells specifically expressing the SCARECROW (SCR) transcription factor. Disrupting $S C R$ function perturbed the formation of these $Q C$ precursor cells (Goh et al., 2016). A recent analysis of LR formation at single cell resolution (Serrano-Ron et al., 72021 ) revealed that although expression of QC markers debuts early during LR formation they are distributed amongst different cell populations and a distinct coherent population only emerges at later stages.

1 during RAM formation in LR, at which stage a fully functional stem cell niche is established remains 02 elusive. Here, we investigate in detail the establishment of the lateral root stem cell niche. In particular we focus on the ontogeny of the QC, considering when each of its features are

4 established: position, slow proliferation, expression of specific markers, and maintenance of the 05 stem cells. We use a combination of tissue identity reporters, live imaging, lineage tracing and cell 06 proliferation assay to conclude that the maturation of the stem cell niche is a progressive process 707 during LR development with acquisition of QC position, molecular identity, quiescence and 08 function being temporally uncoupled. While the QC position, and its role in proximal (shootward) 09 growth are set early during LR formation, its molecular identity, cellular organization and quiescence are only fixed after LR emergence. 


\section{Results}

\section{Classification of lateral root post-emergence}

113 Prior to emergence, LR development follows a nomenclature based on standard morphological 114 stages (Stage I to VII) (Malamy and Benfey, 1997). For the post emergence phases, six types of 115 lateral roots are defined based on their length and angle to the primary root (Kiss et al., 2002).

116 Here, we adapted this latter nomenclature to microscopy image, measuring LR from the junction 117 between the vasculature of the LR and the primary root to the tip of the LR. While we refer to type 1181 as pre-emerged LR, type 2 LR have a maximal length of $250 \mu \mathrm{m}$; type 3 a length of up to $1 \mathrm{~mm}$, 119 type 4 up to $2 \mathrm{~mm}$ and type 5, more than $2 \mathrm{~mm}$ (Fig. 1A).

120 The position of the lateral root stem cell niche is defined before emergence, its identity after

121 In the primary root, the stem cell niche is positioned by complementary patterns of auxin and 122 cytokinin accumulation (Bishopp et al., 2011; Müller and Sheen, 2008; Salvi et al., 2020). There, 123 auxin abundance and auxin signalling are maximal in the QC and the columella cells (Sabatini et 124 al., 1999) while cytokinins signalling is maximal in the root cap, the pro-vasculature above the QC 125 and the distal region of the differentiation zone (Bielach et al., 2012; Marhavý et al., 2014; 126 Montesinos et al., 2020). Auxin and cytokinin tightly regulate each phase of LR development 127 (Nenadić and Vermeer, 2021). We set to see if in the developing LR the position of the new stem 128 cell niche is defined by the same complementary pattern. We visualized the output of auxin and 129 cytokinin signalling during LR development using the pDR5v2::NLS-3xVenus (DR5v2::Venus, 130 (Liao et al., 2015) and TCSn::2xVenus-NLS (TCSn::Venus, (Zürcher et al., 2013) reporters (Fig. 131 1B). Before emergence, DR5v2::Venus signal is present throughout the LRP up to stage IV and 132 after becomes restricted to the tip, as previously observed (Benková et al., 2003). Post emergence, 133 DR5V2::Venus expression is similar to the pattern of the primary root, with highest signal at the 134 apex of the meristem and the columella. TCSn::Venus expression was not detected in the LRP 135 before emergence. This result confirms the previous observations of low level of cytokinin 136 response in the LRP before emergence made with the first generation TCS reporter (Bielach et 137 al., 2012; Chang et al., 2015; Müller and Sheen, 2008). In type 2 emerged LR, TCSn::Venus 138 expression is first detected in the LR stele, then in the columella. In longer LR, TCSn::Venus 139 expression is visible in the outermost layers of the LR columella, an expression pattern reminiscent 140 of the primary root one. Thus while auxin signalling pattern marks the position of the LR stem cell 141 niche from stage IV onward, the complementary cytokinin signalling pattern is only set post 142 emergence. 
A
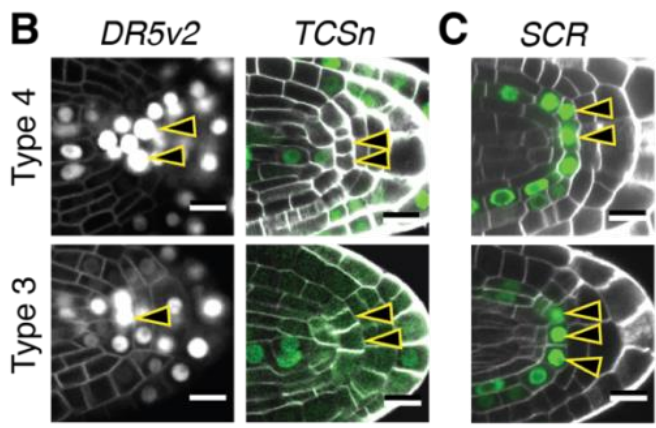

gWOX5
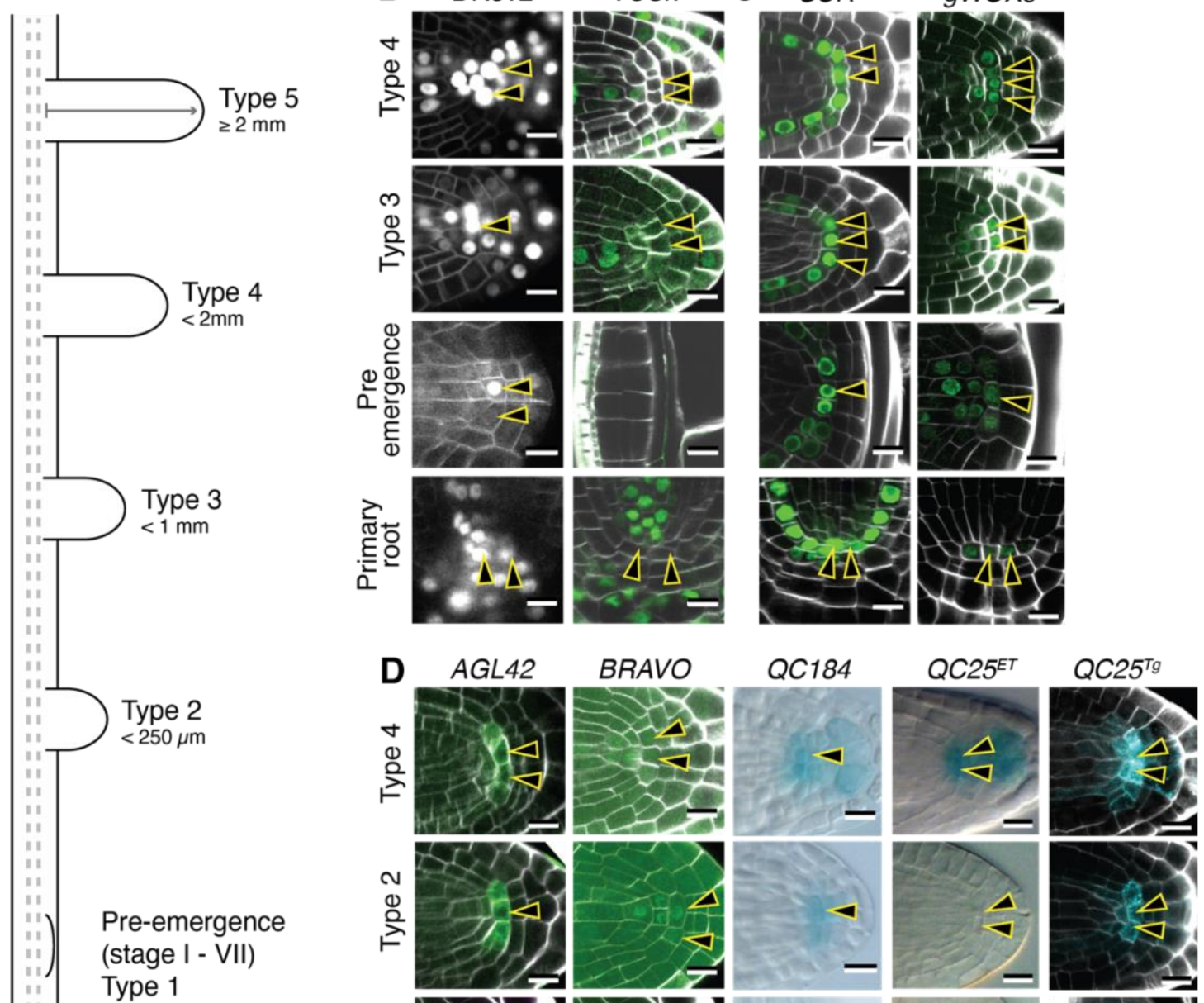

Type 1

Primary

root meristem
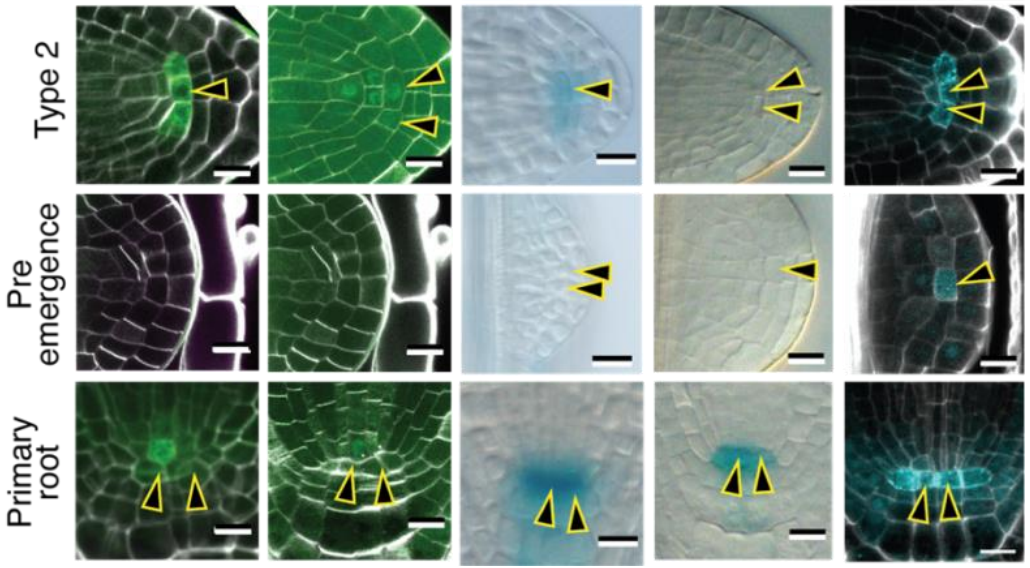

Fig. 1 | Position and identity of the stem cell niche during lateral root development.

(A) Classification of emerged LR based on their length measured from the xylem strands of the primary root to the tip of the lateral root. (B-D) Micrographs of mature primary and developing lateral roots meristems expressing reporters for $(\mathrm{B})$ auxin (DR5V2) or cytokinin (TCSn) signalling, (C) for the niche position ( $g$ WOX5 or SCR), (D) for QC specific markers (AGL4, BRAVO, QC184, QC25ET, QC25 Tg). SCR is a transcriptional reporter (pSCR::nGFP), gWOX5 is a YFP-tagged genomic clone (WOX5-YFP), AGL42 and BRAVO are translational reporters. QC184 and $Q C 25^{E T}$ are GUS enhancer trap lines expressing while in $Q C 25^{T G}$ erCFP is expressed from the cis regulatory sequence located upstream of the $Q C 25^{E T}$ insertion. Images are confocal sections of fluorescent reporters counterstained with Calcofluor white except for QC184 and QC25 $5^{E T}$ that are widefield images of GUS reporters. The apically located cells are indicated with arrowheads. Scale bars: $10 \mu \mathrm{m}$. 
In the primary root, the expression of SCARECROW (SCR) and WOX5 overlap at the 159 quiescent centre (Shimotohno et al., 2018). In LRP, an analysis of the expression pattern of SCR 160 and WOX5 using transcriptional reporters concluded that the LR stem cell niche is established by

161 stage IV, with WOX5 specifically expressed in the apically located cells of the second outermost

162 layer at stage IV/V (Goh et al., 2016). We imaged a SCR transcriptional reporter (pSCR::nGFP)

163 and confirmed it was first detected in the outer layer of stage II LRP and in later stages formed the 164 typical arch marking the stem cell niche and endodermis layer, a profile maintained post 165 emergence (Fig. 1C). We also imaged a YFP-tagged WOX5 genomic clone (WOX5-YFP, (Pi et 166 al., 2015)) and, unlike what was previously reported (Goh et al., 2016), we readily observed 167 WOX5-YFP expression in all cells of stage I-III primordia. From stage IV onward, WOX5-YFP was 168 restricted to the centre of the primordium (Supplemental Fig. S1 and Fig. 1C). Post emergence, 169 WOX5-YFP expression is progressively restricted to three to five cells at the apex of type 4 170 emerged LR (Fig. 1C). Together, these results suggest that the position of the LR stem cell niche,

171 defined by the overlap of an auxin maximum and expression of WOX5 and SCR is defined prior 172 stage IV of LR development, but is only established with cellular precision after emergence, 173 suggesting its identity is only set then.

174 To verify that a specific niche identity comparable to the primary root is only acquired post175 emergence, we monitored the expression of several markers specific of the QC in the primary root. 176 We used two enhancer traps, QC184 and QC25 ${ }^{\mathrm{ET}}$ (Sabatini et al., 2003) and two transcription 177 factors, BRAVO (Vilarrasa-Blasi et al., 2014) and AGL42 (Nawy et al., 2005). Before LR 178 emergence, none of these markers were detected (Fig. 1D). They became visible in type 2 179 (AGL42, BRAVO, QC184) or type 3 (QC25 ${ }^{\mathrm{ET}}$ ) LR (Fig. 1D). The expression of QC25 was 180 previously reported in pre-emergence LR, in two apically located cells from stage IV onward (Goh 181 et al., 2016), much earlier than seen here. However the QC25 reporter used in that study is a 182 transgenic line $\left(\mathrm{QC} 25^{\mathrm{Tg}}\right.$, (ten Hove et al., 2010)) which was constructed by isolation of the 183 sequence flanking the insertion site of the QC25 $5^{\mathrm{ET}}$ enhancer trap used (QC25 $5^{\mathrm{ET}}$ ) here. Whereas 184 in the primary root both versions mark identically the QC, in the developing LR, QC25 $5^{\mathrm{ET}}$ only marks 185 the apically located cells of the niche post-emergence, suggesting, that complex genomic 186 regulation might be at play. Together, these results indicate that the position of the LR root apical 187 meristem is defined before emergence whereas it only expresses specific QC markers once the 188 LR have emerged. 


\section{The cellular layout of the LR stem cell niche is set post-emergence}

193 We then asked when during LR ontogeny, the typical cellular organization of the meristem is 194 established. The QC of the primary root consists of six to twelve apically located cells arranged in 195 a monolayered disk (Dolan et al., 1993; Lu et al., 2021). On sections, two to four apically located 196 cells are typically visible and located between the two cortex-endodermis initials (Fig. 2A). To 197 determine at which stage of LR development this organising centre is first visible and how many 198 cells it has, we imaged by confocal microscopy Calcofluor White stained (Ursache et al., 2018) 199 LRP of 10-day-old Arabidopsis. Prior to emergence, apically located cells between the two cortex200 endodermis initials could only be unambiguously observed from stage $V$ onward (Fig. 2A). Until 201 emergence, their number was variable, with two cells visible only in $40 \%$ of the LRP sections 202 ( $n=105$, Fig. 2B). Post emergence, this variability progressively diminished with most type 4 LR 203 having two cells visible, like in the primary root (Fig. 2B). We confirmed this progressive maturation 204 of the LR stem cell niche by counting the number of QC25 ${ }^{\text {Tg }}$ forming a disk on transverse section 205 (Fig. 2C, D). While pre-emergence, less than 5 cells were typically observed, this number 206 increased as the LR mature post-emergence to reach the values seen in the primary root meristem 207 (Fig. 2D). Together, these data show the typical cellular layout of the root meristem is only fixed 208 after emergence and indicates that the cellular organization of the LR organising centre 209 progressively matures. The primary root meristem has been shown to progressively acquire its 210 organization post-germination (Salvi et al., 2020). We thus asked whether the maturation of the 211 LR stem cell niche post-emergence follows a similar path to the primary root meristem post212 germination. We counted the number of apically located cells in the primary root meristem during 213 germination and observed that on average two cells were already visible on section at 0,24 or $48 \mathrm{~h}$ 214 post imbibition (Fig. S2). Thus the establishment of the cellular layout of the primary and lateral 215 root stem cell niches follow different path. 
A
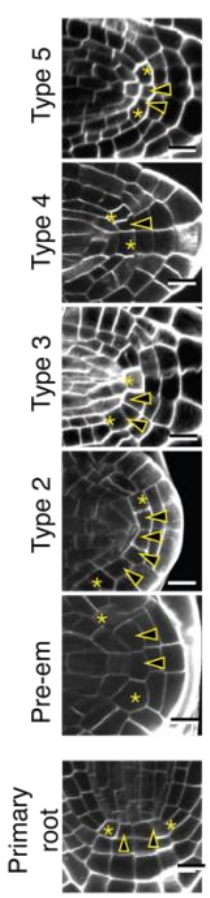

B

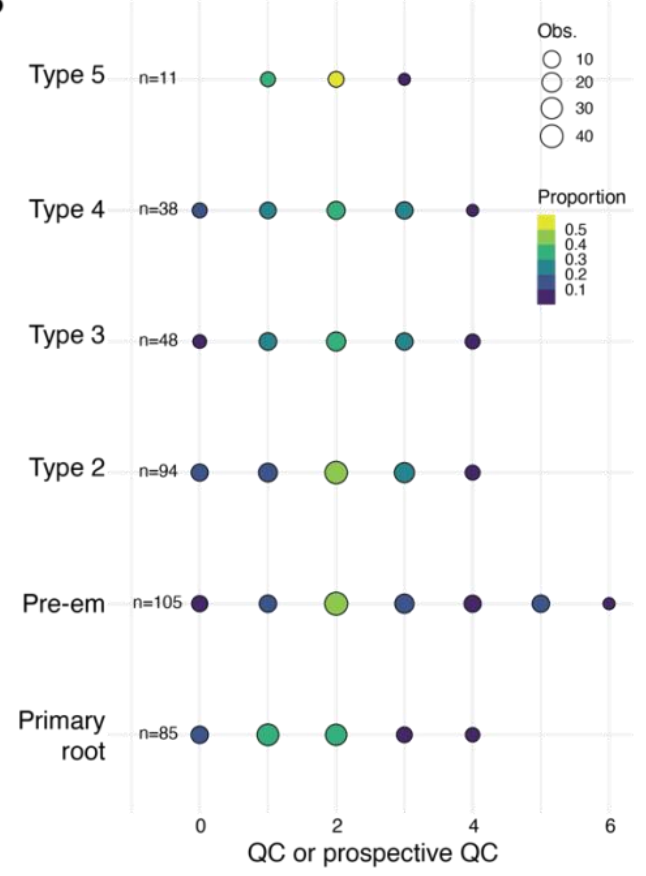

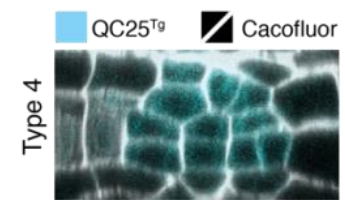

\section{D}

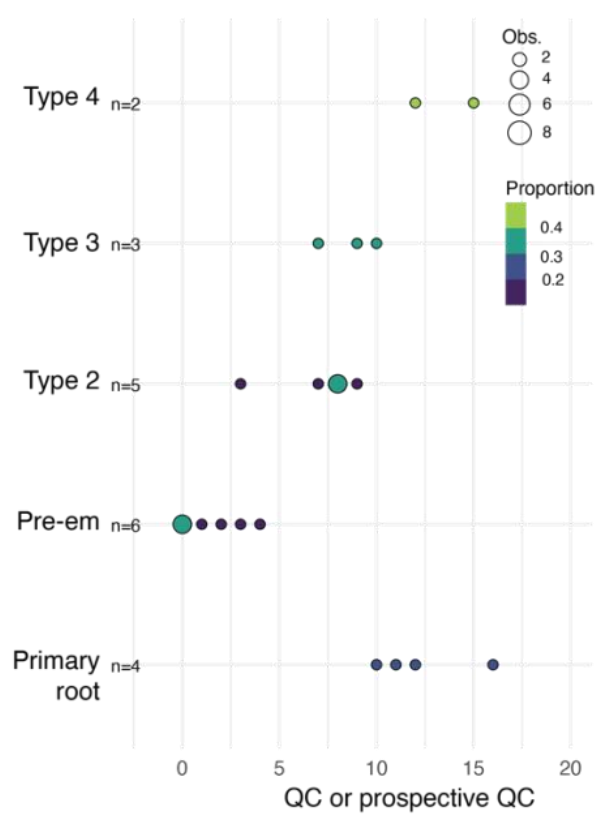

Fig. 2 | Cellular layout of developing apical meristem of the lateral root.

(A) Confocal sections of the developing root apical meristem and each class of LR counterstained with Calcofluor white in 10-day-old Arabidopsis. The QC or apically located prospective QC cells (arrowheads) and the cortex-endodermal initial (stars) are indicated.

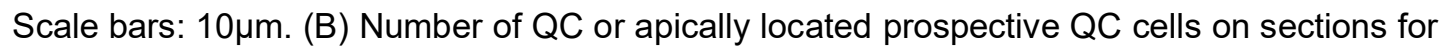
the different classes of roots. (C) Cross-sections of 10-day-old QC25 $5^{T g}$ seedlings counterstained with Calcofluor white. (D) Total number of QC cells on sections for the different classes of roots. In $B \& D$, the size of the circle is proportional to the number of observations (Obs.), and the colour represents the relative proportion of observations within a given class. The total number of observations per given classes is indicated $(n)$. 


\section{The LR stem cell niche becomes quiescent shortly after emergence}

228 A distinctive feature of the primary root meristem is the low mitotic activity of the QC cells. We thus 229 asked when cells become quiescent during LR formation. For this we quantified the proportion of 230 proliferating apically located cells using the G2-S phase label 5-ethynyl-2'-deoxyuridine (EdU) 231 during LR ontogeny, before and after emergence. Plants expressing the pSCR::nGFP reporter 232 were incubated with EdU for 8h, fixed, and LR were imaged. We quantified the fraction of SCR 233 positive cells in between the two cortex-endodermis initials (apically located cells) that are EdU 234 positive (Fig. 3A). Before emergence, $>75 \%$ of apically located cells of stage IV to VI primordia 235 incorporated EdU (Fig. 3B) indicating that most cells were proliferating. As the primordia were 236 incubated for $8 \mathrm{~h}$ with EdU, we concluded that the cycling time of these cells is comparable to the 237 one previously measured for the LR ( 7.5h, (von Wangenheim et al., 2016)). To directly monitor 238 the mitotic activity of these apically located cells before emergence, we used the cell cycle 239 progression reporter, Cytrap (Yin et al., 2014), expressing the S/G2 phase marker 240 pHTR2::CDT1a(C3)-RFP that we crossed to the QC25 $5^{\text {Tg }}$ reporter to mark the position of the future 241 QC cells from stage IV onward (Goh et al., 2016). We confirmed that most of the cells expressing 242 the QC25 ${ }^{\mathrm{Tg}}$ reporter expressed the Cytrap S-phase marker indicating that they were mitotically 243 active (Supplemental Fig. S3). We then used light sheet live imaging of developing LRP expressing 244 SCR::nGFP. We observed several divisions of SCR-expressing apically located cells 245 (Supplemental Fig. S3). Together, these data indicate that before emergence, apically located 246 cells are actively proliferating and quiescence must occur once the LR emerges.

Emerging LR are covered by a cutin-based cuticle (Berhin et al., 2019) that blocks the

248 uptake of EdU by the young LR (Supplemental Fig. S4) and consequently prevented us to analyse

249 EdU incorporation in young emerging LR to pinpoint when post-emergence apically located cells 250 become quiescent. To circumvent this, we monitored EdU incorporation in the defective in cuticular 251 ridges ( $d c r)$ mutant with altered cutin biogenesis and enhanced permeability (Berhin et al., 2019). 252 LR emergence in the $d c r$ mutant is slower than wild type and some primordia are mis-shaped 253 (Berhin et al., 2019), nevertheless as in wild type most apically located cells in dcr LRP 254 incorporated EdU before emergence, indicating that the mutation does not impact the proliferative 255 behaviour of the primordia (Supplemental Fig. S4). After emergence, the proportion of proliferating 256 apically located cells dropped to less than $25 \%$ already in type 2 LR ( $<250 \mu \mathrm{m}$ long), indicating 257 that quiescence is quickly established after emergence (Fig. 3C). To visualise the moment when 258 apically located cells stop proliferating, we performed live imaging of LR expressing the 259 Cytrap/QC25 $5^{\text {Tg }}$ reporters and tracked the position of apically located cells with the QC25 $5^{\text {Tg }}$ marker.

260 We observed the disappearance of the S-phase Cytrap marker in two apically located cells shortly 261 after emergence (130 $\mu \mathrm{m}$ long, Fig. 3D). Together, these results show that quiescence of the LR 262 niche cells is established shortly after emergence. 
A

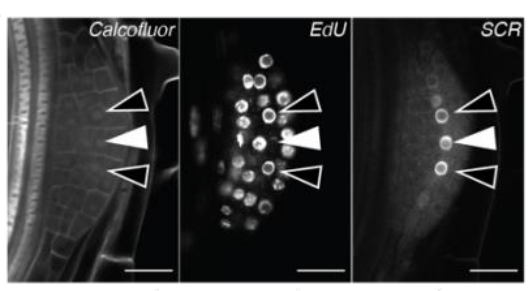

B

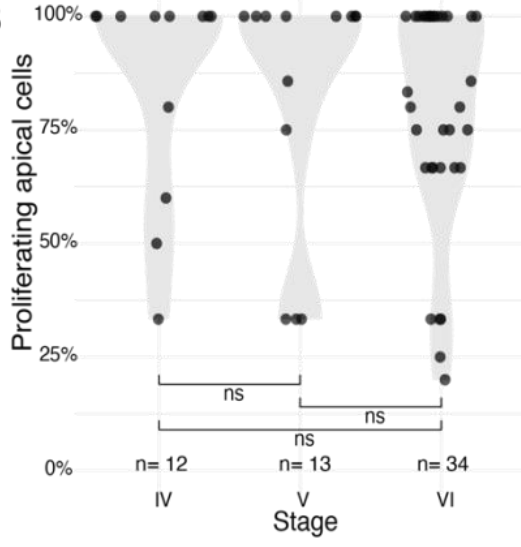

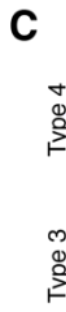

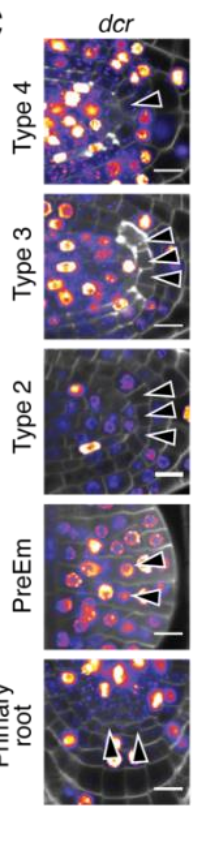

D

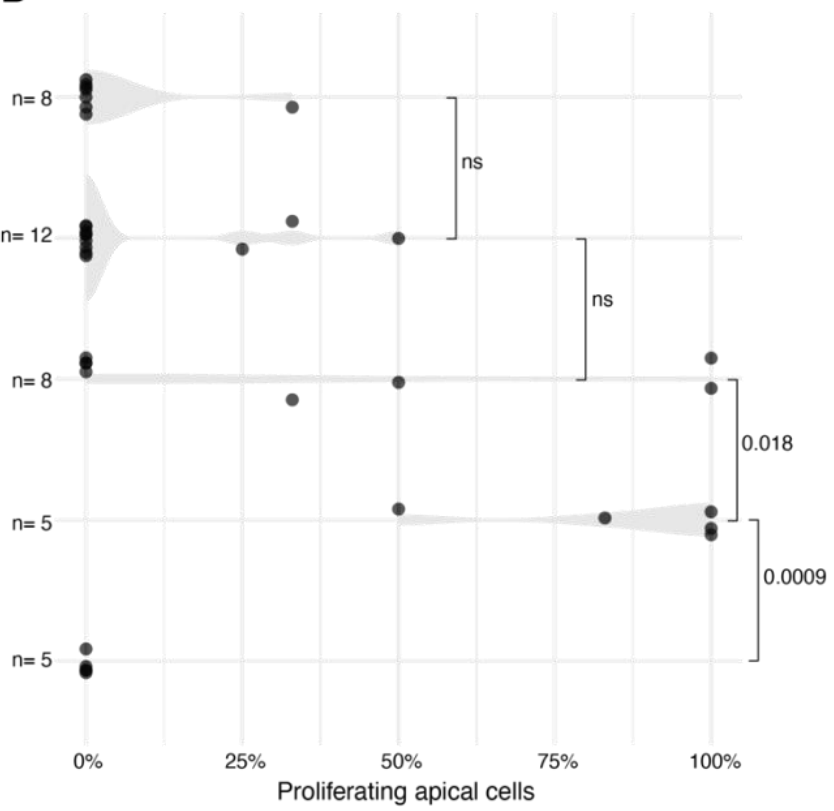

E
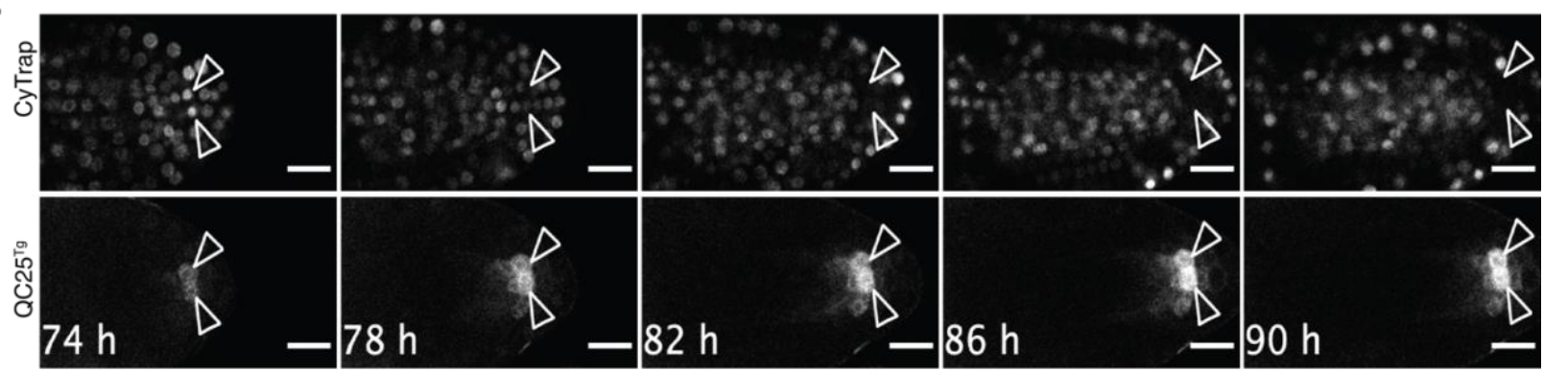

Fig. 3 | Post emergence quiescence of the LR stem cell niche

(A) Confocal sections of a pre-emergence lateral root primordium expressing $p S C R:: n G F P$ $(S C R)$ counterstained with Calcofluor White and the S-phase label EdU. The open arrowheads indicate apically located cells expressing $S C R$ and positive for EdU (8h incubation), while the filled one shows a SCR positive apical cell with no EdU staining. (B) Proportion of proliferating apically located cells in stage IV-VI lateral root primordia. Each point represents a primordium. The number of observed primordia is indicated. The distributions do not differ from each other according to Student's t test with Bonferroni correction. (C) Confocal sections of primary root and lateral root apical regions at different stages of development in 10-day-old dcr plants counterstained with Calcofluor White (grey) and the S-phase label EdU (color). Arrowheads indicate the apically located cells. (D) Quantification of the proportion of proliferating apically located cells in the developing root apical meristem at different stages of LR development. The number of observed primordia is indicated. The level of significance of each comparison is indicated (Student's t test with Bonferroni correction). (E) Time lapse confocal imaging of a type 2 emerged LR expressing the S-G2 phase marker CyTrap and the apical cell marker $Q C 25^{T g}$. The arrowheads track the position of two apically located cells. Note the disappearance of the S-phase marker in these cells between $74 \mathrm{~h}$ and $82 \mathrm{~h}$. Hours indicate the time since induction of LR formation by gravistimulation. Scale bars: A,C: $10 \mu \mathrm{m}, \mathrm{E}: 20 \mu \mathrm{m}$. 


\section{Biphasic acquisition of the stem cell niche organiser function in LR}

283 The primary root stem cell niche acts as an organising centre that maintains cells in its direct 284 contact in a stem cell state (Bennett et al., 2014; Pi et al., 2015; van den Berg et al., 1997) and 285 generates tissues in both distal (rootward) and proximal (shootward) directions (Rahni et al., 2016).

286 Whereas the position of the LR stem cell niche is set before emergence, quiescence and the final 287 cellular layout are only established after. This raises the question of when is the niche starting to 288 function like an organising centre able to generates tissues in both distal and proximal directions.

We first looked at the expression of markers for the proximal (enhancer trap line Q0990 290 (Radoeva et al., 2016)) or distal (SOMBRERO, (Bennett et al., 2010)) axis during LR ontogeny. In 291 the primary root, Q0990 expression marks the vascular cells and the QC (Radoeva et al., 2016). 292 In the developing LR, Q0990 is first detected at stage IV, marking the central elongated cells that 293 will form the LR stele and is excluded from the apically located cells whose position correspond to 294 the future stem cell niche (Fig. 4A). It is only post-emergence, in type 2 LR, that Q0990 expression 295 starts to be visible in these apically located cells in addition to the stele, confirming that these cells 296 only acquire a QC-like identity post-emergence (Fig. 4A). In the primary root meristem, 297 SOMBRERO (SMB) is expressed in all the differentiated cells of the root cap and excluded from 298 the columella stem cells (Bennett et al., 2010) and is thus a marker for differentiation in the distal 299 direction. We did not detect expression of the SMB reporter pSMB::nGFP in LR before emergence. 300 In LR that just emerged, the reporter is first detected in the distal layers of the root cap, but 301 excluded from the cells abutting the apically located cells (as previously reported by (Du and 302 Scheres, 2017). As LR grow longer, the number of columella layers increases (see below) and 303 these express $S M B$, but not the cells in direct contact to the apically located cells. Taken together, 304 it appears that proliferation in the proximal (shootward) direction is established before LR 305 emergence, while it is only post-emergence that proliferation in the distal direction is set up (Fig. 306 4A). These observations suggest that it is only post emergence that columella stem cells (CSC) 307 are specified. To verify this, we first quantified the number of columella cells layers. In the primary 308 root four to eight layers of columella cells are homeostatically maintained through the balanced 309 activity of the columella stem cell and the sloughing off of the outermost layer of root cap (Fendrych 310 et al., 2014). Before LR emergence, we observed two layers of columella and this number 311 progressively increased to five layers as LR matured post-emergence (Fig. 4B). We then looked 312 at the distribution of starch granules, a marker of differentiated columella cells typically absent 313 from the CSC (van den Berg et al., 1995), in developing LR. mPS-PI staining (Truernit et al., 2008) 314 of LR showed that starch granules are first formed post-emergence in columella cells, confirming 315 previous observations (Guyomarc'h et al., 2012; Kiss et al., 2002), but also revealed starch in the 316 cells directly abutting the apically located cells. Interestingly, a layer of cells devoid of starch 317 granules next to the apically located cells is formed only in type 5 LR (>2mm) (Fig. 4C). Together 
318 these data show that before emergence the apically located cells are able to maintain as stem cell

319 the abutting cells in the proximal (shootward) direction but only acquire this capacity post320 emergence in the distal (rootward) direction.

To confirm this, we induced clones in the SCR domain and checked whether the clones

322 derived from the central cells marked the proximal and/or distal domains. Observation of post-

323 emergence LR expressing the p35S::lox-Ter-lox:erCFP / pSCR::CRE-GR construct (Efroni et al.,

324 2016) and treated with DEX for $38 \mathrm{~h}$ resulted in erCFP signal in the apically located cells, the CEls,

325 and some endodermal cells. We also observed erCFP expression in the provascular cells directly

326 adjacent to the apically located cells but none in the cells located distally (Fig. 4D). Thus, the LR

327 stem cell niche acquires its ability to bidirectionally generate tissues in two phases: it contributes

328 to growth in the proximal direction before emergence and in the distal direction only post-

329 emergence, concomitantly to the establishment of its mitotic quiescence and expression of specific

330 marker genes. 
A

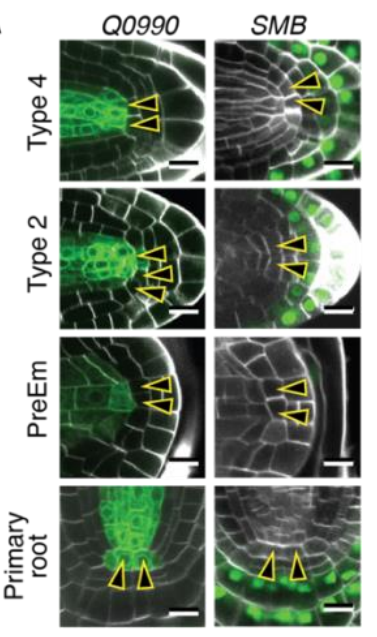

B

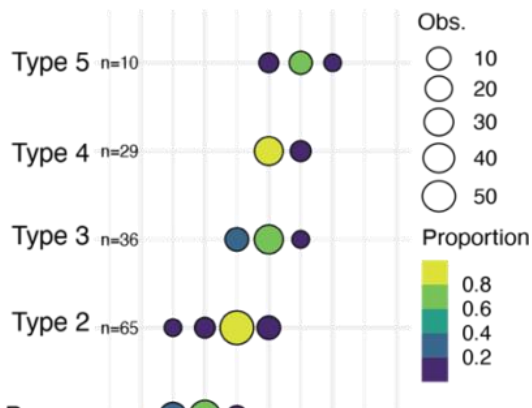

Pre-em n=62 $\bigcirc \bullet$

Primary $n=8$

root

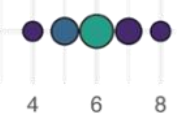

Columella cells layer

C

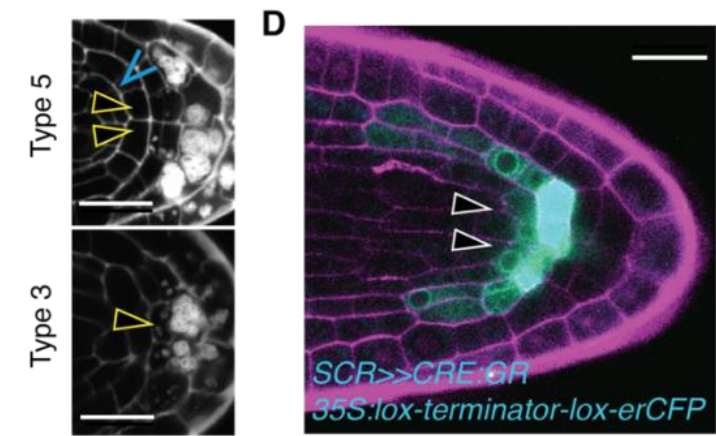

Fig. 4 | Biphasic acquisition of the stem cell niche organiser function in LR

(A) Confocal sections of calcofluor white counterstained primary root meristem and each class of LR in 10-day-old Arabidopsis expressing the proximal (Q0990) and distal (SMB) identities reporters. The open arrowheads indicate apically located cells in lateral roots and the $Q C$ in the primary root. (B) Number of columella cell layers in the primary root and for the different classes of lateral roots. The size of the circle is proportional to the number of observations (Obs.), and the colour represents the relative proportion of observations within a given class. (C) Confocal sections of mPS-PI stained primary root meristem and each class of LR in 10day-old Arabidopsis. The open arrowheads indicate apically located cells in lateral roots and the $Q C$ in the primary root while the blue arrow point the layer of columella stem cells. (D) Confocal section of a PI counterstained type 2 lateral root (length: $112 \mu \mathrm{m}$ ) 38h after generation of clones in the SCR domain by dexamethasone treatment. Arrowheads indicate provascular initials resulting from the division of the $S C R$-expressing apically located cells. Scale bars are $10 \mu \mathrm{m}(\mathrm{A}, \mathrm{D})$ and $20 \mu \mathrm{m}(\mathrm{C})$. 


\section{Discussion}

348 Here, we characterised the ontogeny of the root apical meristem (RAM) in lateral root, with a 349 particular emphasis on the QC. We used reporters for tissue identity, live imaging, lineage tracing 350 and cell proliferation assay and conclude that while the QC position and its role in proximal 351 (shootward) growth are set early during LR formation, its molecular identity, cellular organization 352 and quiescence are only fixed after LR emergence. The different attributes of the primary RAM 353 QC are thus progressively acquired during LR formation, suggesting a progressive maturation 354 process of this post-embryonic meristem.

356 Despite the similarities in cellular organisation and gene expression profiles between the primary 357 and LR RAM and the essential role played by the QC in organising and coordinating the primary 358 RAM (Rahni et al., 2016), there were no comprehensive analysis of the ontogeny of the QC in LR. 359 Previous reports analysed either the expression patterns of genes of the primary RAM during LR 360 formation (Tian et al., 2014a) or focused on cell differentiation associated with acquisition of 361 gravitropic and phototropic responses in LR (Guyomarc'h et al., 2012; Kiss et al., 2002; Waidmann 362 et al., 2020). Our analysis reveals interesting insights into the mechanisms of LR RAM maturation. 363

364 Like in the primary RAM, the pattern of auxin signalling and of SCR and WOX5 expression defines 365 the position of the QC during the early stages of LR development. This result agrees with a prior 366 report (Goh et al., 2016) and supports the view that a key transition in LR organogenesis occurs 367 at the stage IV-V transition, when the primordium breaks through the overlying endodermis layer, 368 becomes radially symmetric (Lucas et al., 2013) and acquires autonomy relative to the auxin fluxes 369 from the parent root (Laskowski et al., 1995). Yet, our observations nuance the conclusion that the 370 LR QC is established at this early stage (Goh et al., 2016). Indeed, we observe variation in the 371 cellular organisation of the LR RAM prior to emergence and a primary root like cellular organisation 372 of the RAM is only fixed once the LR has emerged. Our analysis of cell proliferation using EdU 373 incorporation or long term imaging revealed that quiescence of the apically located cells in the LR 374 RAM is only established after emergence. This quiescence is concurrent to the onset of expression 375 of most molecular markers associated with the primary RAM (AGL42, BRAVO, QC184 and 376 QC25 $\left.{ }^{\mathrm{ET}}\right)$. An exception being QC25 ${ }^{\mathrm{Tg}}$ which marks the position of the apically located cells from 377 stage IV/V albeit a stage when these cells still proliferate. The difference of behaviour between $378 \mathrm{QC}^{\mathrm{Tg}}$ and QC25 $5^{\mathrm{ET}}$ reporters suggests that whereas the positional cues responsible for the 379 localised expression of the $Q C 25^{\mathrm{Tg}}$ reporter are present in its promoter sequence, they are 380 overridden in the enhancer trap line until the cells become quiescent. In addition to revealing the 381 existence of genomic regulations associated with the quiescence of the apically located cells, this 382 results support the temporal decoupling between positioning the prospective LR QC cells and their 
383 actual maturation and entry into quiescence. Our results support that the position of the LR QC is 384 set before emergence but only activated post-emergence as it had been suggested earlier 385 (Celenza et al., 1995; Malamy and Benfey, 1997). A recent single cell analysis of the developing 386 LR has shown that expression of genes typically associated with the QC in the primary RAM can 387 be readily detected in stages I to III LR, yet distributed amongst different clusters that only form a 388 distinct coherent population at later stages (Serrano-Ron et al., 2021). Our observation of WOX5389 YFP expression in most cells of stage II LR supports this notion of a progressive specification of 390 cell identities in the early phases of LR organogenesis. This early expression of WOX5 is raising 391 questions about of the role played by this essential factor for QC identity at early stages. 392 Interestingly, (Goh et al., 2016) reported a very specific onset of WOX5 expression in four apically 393 located cells at stage IV/V, in apparent contradiction to our and others observations (Ditengou et 394 al., 2008; Du and Scheres, 2017). The absence of essential cis-regulatory element(s) in the 395 transcriptional reporter used by Goh et al. (pWOX5::n3GFP) compared to the YFP-tagged 396 genomic clone used (Pi et al., 2015) could account for the differences in expression pattern.

398 Current models assign to the QC an organizer function that signals to the surrounding cells and 399 actively maintains their "stemness". An alternative view is that the position of the stem cells 400 organizer results from two opposing axis that reciprocally control each other's differentiation (Rahni 401 et al., 2016). In this so called "stagnation" model, the QC corresponds to the location where cells 402 are not displaced by their neighbours as result of the activity of shootward and rootward gradients 403 of division and differentiation. Where these two gradients meet, cell division is minimal and a 404 stagnation zone is created on either side of which more rapidly dividing cells are bound to 405 displaced their daughter cells in opposite directions (Rahni et al., 2016). In this model, the 406 stemness of stem cells is the result of a passive mechanical process and does not rely on 407 quiescence of the QC. Our results show that the growth axis of the LR are established in distinct 408 phases with the proximal (shootward) growth axis established pre-emergence and the distal 409 (rootward) one after emergence, concomitantly to the stabilisation of number of prospective QC 410 cells, the slowdown of their cell division rate and the activation of QC specific markers. These data 411 support the stagnation model in which the position and maturation of the LR QC cells is fixed once 412 the two opposite gradients are established. Activation of QC specific identities and entry in 413 quiescence would be an emerging property of the slowdown in cell division rate at the position 414 where the two growth axis meet. Quiescence, a late emerging property in LR, would thus not be 415 instrumental in organizing the stem cell niche, but a results of the two diverging growth axis, alike 416 the region of mostly calm weather at the center of a cyclone results from diverging convection 417 flows (Rahni et al., 2016). This shift in the importance of the QC slow mitotic activity is supported 418 by the observation that loss of QC-quiescence has no effect on root growth (Cruz-Ramírez et al., 419 2013). 


\section{Material and Methods}

\section{Plant material and growth conditions}

422 We used the previously described lines: DR5v2::3xYFP:NLS (sC111) (Vilches Barro et al., 2019), 423 pTCSn::2xVenus:NLS (El Arbi et al., 2021), gWOX5::WOX5:YFP in wox5-1 (Pi et al., 2015), 424 pAGL42::truncAGL42:GFP (Nawy et al., 2005), pBRAVO::BRAVO:GFP (Vilarrasa-Blasi et al., 425 2014), pQC184::GUS (in the gWOX5::WOX5:YFP in wox5-1) (Pi et al., 2015), pQC25er::CFP 426 (QC25 $5^{\text {Tg }}$ (Goh et al., 2016), Cytrap (pHTR2::CDT1a (C3)-RFP, pCYCB1::CYCB1;1-GFP) (Yin et 427 al., 2014) and pSCR>>CRE:GR/35S:Iox-terminator-lox-CFP (Efroni et al., 2016) The enhancer 428 trap lines Q0990 (Radoeva et al., 2016), QC25 ${ }^{\mathrm{ET}}$ (Sabatini et al., 2003) were described previously. 429 For crosses between lines, F1 generation was used. The dcr mutant was previously described 430 (Berhin et al., 2019). Seeds were surface sterilized (Sodium hypochlorite $5 \%$ and $0.05 \%$ Tween 43120 or Ethanol $70 \%$ and $0.05 \%$ Triton X-100) and placed on $1 / 2$ Murashige and Skoog (MS) medium 432 containing $0.8 \%$ agar (Duchefa). Following stratification $\left(4^{\circ} \mathrm{C}\right.$ in the dark, $\left.>\mathrm{t} 24 \mathrm{~h}\right)$, seedlings were 433 grown at $22^{\circ} \mathrm{C}$ vertically under long day conditions ( $16 \mathrm{~h}$ light / $8 \mathrm{~h}$ dark). For the lineage tracking 434 experiments $15 \mu \mathrm{M}$ dexamethasone were used for $24 \mathrm{~h}$.

\section{Construction of vectors and plant transformation}

437 The transcriptional reporters pSCR::nGFP (pSCR::H2B-3xGFP::tRBCS) and pSMB::nGFP 438 ( $p S M B:: H 2 B-3 x G F P:: t R B C S$ ) reporters were generated using GreenGate assembly 439 (Lampropoulos et al., 2013). For pSCR, 2114bp upstream of ATG were used and 3246bp for 440 pSMB. Agrobacterium tumefaciens (Agl-0) based plant transformation was carried out using the 441 floral dip method (Clough and Bent, 1998). All plant lines examined were homozygous if not 442 indicated otherwise. Homozygosity was determined by antibiotic resistance and verification of the 443 fluorescent fusion proteins at the microscope.

444

\section{Microscopy}

446 Unless otherwise specified, imaging was performed on seedlings fixed for 30 min with PFA 4\% in 447 PBS $1 \mathrm{X}$ at room temperature, Calco Fluor white staining was performed as previously described 448 (Ursache et al., 2018). Seedlings were cleared with either $50 \%$ glycerol for $24 \mathrm{~h}$ or ClearSee 449 solution for up to a week (Kurihara et al., 2015). Root meristems were imaged on medial sections 450 on a Leica SP8 confocal microscope with $63 x, N A=1.4$ oil immersion objective or a $40 x, N A=1.3$ 451 oil immersion objectives. Calcofluor White fluorescence was detected using the $405 \mathrm{~nm}$ excitation 452 laser line, and $425-475 \mathrm{~nm}$ emission range. The number of apically located cells is obtained by 453 counting all cells between the cortex-endodermis initial. For Edu incorporation, Alexa fluor 647nm 454 detection was achieved using the $638 \mathrm{~nm}$ excitation laser line in the 650-695nm range. For the 455 Cytrap cell cycle progression reporter (Yin et al., 2014), the $S$ and G2 phases marker 
456 pHTR2::CDTa (C3)-RFP was detected using the $552 \mathrm{~nm} \mathrm{~nm}$ excitation laser line in the $600 \mathrm{~nm}$ to $457650 \mathrm{~nm}$ emission range. The G2/mitosis phases marker was detected using the $488 \mathrm{~nm}$ excitation 458 laser line in the 500 to $550 \mathrm{~nm}$ emission range. For live imaging, a Leica SP8 was used with a 20X $459 \mathrm{NA}=1.2$ oil immersion objective. Lateral root growth was induced by $52 \mathrm{~h}$ of gravistimulation $\left(180^{\circ}\right)$ 460 in seedlings of 4 to 6 days after germination (dpg). Seedlings were placed in an imaging chamber 461 and covered with a piece of $1 / 2$ MS medium for imaging, as described in (Marhavy and Benkova, 462 2015). Stacks were acquired every 2 hours with $1 \mu \mathrm{m} z$-steps. For live imaging of the SCR reporter, 463 the pSCR::nGFP reporter was crossed to a line expressing $p U B Q 10:: P I P 1,4: G F P \times 3$; 464 pGATA23::H2B:nCherryx3 (stPVB003, (Vilches Barro et al., 2019) and imaging was done on a 465 MuViSPIM (Luxendo, Bruker, Germany) light sheet microscope equipped with a Nikon NIR Apo $46640 \mathrm{XNA}=1.2$ water objective for detection. Movies were acquired with a $z$-step of $0.250 \mu \mathrm{m}$, and a 467 temporal resolution of $30 \mathrm{~min}$.

\section{Histochemical analysis}

471 Staining of starch granule in the columella cells was performed as described previously (Truernit 472 et al., 2008). GUS staining was performed as described previously (Maizel and Weigel, 2004) 473 followed by fixation in $4 \% \mathrm{HCl}, 20 \%$ methanol solution, for 15 min at $70^{\circ} \mathrm{C}$, followed by $7 \% \mathrm{NaOH}$ 474 and $60 \%$ ethanol for $15 \mathrm{~min}$ at room temperature. Seedlings were then cleared in successive 475 ethanol baths for 10 mins (40\%, 20\%, 10\%), followed by 10 min incubation in $25 \%$ glycerol and $4765 \%$ ethanol. Finally seedlings are placed in $50 \%$ glycerol and stored at $4{ }^{\circ} \mathrm{C}$ until imaging. Seedlings 477 were mounted in 50\% glycerol for imaging with DIC microscopy using an Axio Imager. M1 (Carl 478 Zeiss, Oberkochen, Germany) with a $40 \mathrm{X}$ objective.

\section{EdU incorporation}

481 For Edu incorporation in LRP before emergence, LR formation was induced by $30 \mathrm{~h}$, 36h, or $42 \mathrm{~h}$ 482 of gravistimulation, and seedling were transferred on plates containing $1 \mu \mathrm{M}$ of EdU in $1 / 2 \mathrm{MS}$ plates 483 for the last $8 \mathrm{~h}$ of the gravistimulation period. For Edu incorporation in emerged lateral root (in $d c r$ 484 mutant), LR was induced by $48 \mathrm{~h}, 72 \mathrm{~h}, 96 \mathrm{~h}$ or $120 \mathrm{~h}$ of gravistimulation, and EdU incorporation was 485 performed during the last $24 \mathrm{~h}$ of the gravistimulation using $0.5 \mu \mathrm{M}$ of EdU in $1 / 2 \mathrm{MS}$ plates. EdU 486 detection was performed using a slightly modified version of the previously described protocol 487 (Kotogány et al., 2010). Briefly, seedlings were fixed for $15 \mathrm{~min}$ at room temperature in the dark 488 with 4\% PFA in PBS, washed 2 times 1 min with 3\% BSA in PBS, incubated 20 min with $0.5 \%$ 489 Triton X-100 in PBS and washed 2 times 1 min with 3\% BSA in PBS, then incubated with the Click$490 \mathrm{iT}^{\mathrm{TM}}$ (Click-iT $\mathrm{T}^{\mathrm{TM}}$ EdU Cell Proliferation Kit for Imaging, Alexa Fluor ${ }^{\mathrm{TM}} 647^{\mathrm{TM}}$ Invitrogen, Thermofisher 491 , C10340) reaction cocktail for $30 \mathrm{~min}$ at room temperature in the dark, rinsed with PBS and 492 washed with $3 \%$ BSA in PBS 3 times for 1 min. Seedlings were then washed 2 times with PBS 
493 and cell walls were stained with $0.1 \%$ Calco fluor white (Fluorescent brightener 28 F3543-1G 494 Sigma-Aldrich) in PBS for $30 \mathrm{~min}$ in the dark. After rinsing, seedlings were transferred to $50 \%$ 495 glycerol for at least $16 \mathrm{~h}$ before imaging. Apically located cells showing EdU incorporation or 496 expressing the pHTR2::CDTa (C3)-RFP marker (Cytrap) were considered as proliferative. The 497 proportion of proliferating apically located cells was obtained by dividing the number of proliferative 498 apically located cells divided by the total number of apical cell on that section. 


\section{Supplementary data}

500 Supplementary data are available online.

501 Fig. S1. Expression of WOX5 in early lateral root primordia

502 Fig. S2. Expression of SCR during germination

503 Fig. S3. Apically located cells stop to proliferate post-emergence

504 Fig. S4. EdU incorporation and cell proliferation in LR of wild type and dcr mutant

505

\section{Acknowledgements}

507 We thank J. Dubrovsky for critically reading the manuscript, and the Caño-Delgado, Efroni, Greb, Laplaze,

508 Laux, Lohmann, Nawrath and Palatnik labs for sharing resources. The authors gratefully acknowledge the 509 data storage service SDS@hd supported by the Ministry of Science, Research and the Arts Baden-

510 Württemberg (MWK) and the German Research Foundation (DFG) through grant INST 35/1314-1 FUGG 511 and INST 35/1503-1 FUGG.

512

\section{Author contribution}

514 Conceptualization: AM

515 Data Acquisition and curation: BB, AM

516 Formal Analysis: BB, AM

517 Funding Acquisition: AM

518 Methodology: AM, BB, LB, ML

519 Project Administration: AM

520 Resources: BB, LB, ML

521 Supervision: AM

522 Visualization: BB, AM

523 Writing - Original Draft: BB, AM

524 Writing - Review and Editing: BB, AM 
bioRxiv preprint doi: https://doi.org/10.1101/2022.02.18.481036; this version posted February 19, 2022. The copyright holder for this

preprint (which was not certified by peer review) is the author/funder, who has granted bioRxiv a license to display the preprint in perpetuity. It is made available under aCC-BY-NC-ND 4.0 International license.

\section{Conflicts of interests}

528 The authors declare no competing interests.

529

\section{Funding}

531 This work was supported by the DFG FOR2581.

532

\section{Data availability}

534 The data supporting the findings of this study are available from the corresponding author upon 535 request. 


\section{REFERENCES}

Benková, E., Michniewicz, M., Sauer, M., Teichmann, T., Seifertová, D., Jürgens, G. and Friml, J. (2003). Local, Efflux-Dependent Auxin Gradients as a Common Module for Plant Organ Formation. Cell 115, 591-602.

Bennett, T., van den Toorn, A., Sanchez-Perez, G. F., Campilho, A., Willemsen, V., Snel, B. and Scheres, B. (2010). SOMBRERO, BEARSKIN1, and BEARSKIN2 regulate root cap maturation in Arabidopsis. Plant Cell 22, 640-654.

Bennett, T., van den Toorn, A., Willemsen, V. and Scheres, B. (2014). Precise control of plant stem cell activity through parallel regulatory inputs. Development 141, 4055-4064.

Berhin, A., de Bellis, D., Franke, R. B., Buono, R. A., Nowack, M. K. and Nawrath, C. (2019). The Root Cap Cuticle: A Cell Wall Structure for Seedling Establishment and Lateral Root Formation. Cell 176, 1367-1378.e8.

Bielach, A., Podlesáková, K., Marhavy, P., Duclercq, J., Cuesta, C., Müller, B., Grunewald, W., Tarkowski, P. and Benková, E. (2012). Spatiotemporal regulation of lateral root organogenesis in Arabidopsis by cytokinin. Plant Cell 24, 3967-3981.

Bishopp, A., Benkova, E. and Helariutta, Y. (2011). Sending mixed messages: auxin-cytokinin crosstalk in roots. Curr. Opin. Plant Biol. 14, 10-16.

Brumos, J., Robles, L. M., Yun, J., Vu, T. C., Jackson, S., Alonso, J. M. and Stepanova, A. N. (2018). Local Auxin Biosynthesis Is a Key Regulator of Plant Development. Dev. Cell 47, 306-318.e5.

Byrne, J. M. (1973). The root apex of Malva sylvestris. lii. Lateral root development and the quiescent center. Am. J. Bot. 60, 657-662.

Celenza, J. L., Grisafi, P. L. and Fink, G. R. (1995). A pathway for lateral root formation in Arabidopsis thaliana. Genes Dev. 9, 2131-2142.

Chang, L., Ramireddy, E. and Schmülling, T. (2015). Cytokinin as a positional cue regulating lateral root spacing in Arabidopsis. J. Exp. Bot. 66, 4759-4768.

Clough, S. J. and Bent, A. F. (1998). Floral dip: a simplified method for Agrobacterium-mediated transformation of Arabidopsis thaliana. Plant J. 16, 735-743.

Clowes, F. A. L. (1954). The Promeristem and the Minimal Constructional Centre in Grass Root Apices. New Phytol. 53, 108-116.

Clowes, F. A. L. (1956). Nucleic Acids in Root Apical Meristems of Zea. New Phytol. 55, 29-34.

Clowes, F. A. L. (1958). Development of Quiescent Centres in Root Meristems. New Phytol. 57, 85-88.

Clowes, F. A. L. (1959). Reorganization of Root Apices after Irradiation. Ann. Bot. 23, 205-210.

Clowes, F. A. L. (1978). Origin of the quiescent centre in Zea mays. New Phytol. 80, 409-419.

Cruz-Ramírez, A., Díaz-Triviño, S., Wachsman, G., Du, Y., Arteága-Vázquez, M., Zhang, H., Benjamins, R., Blilou, I., Neef, A. B., Chandler, V., et al. (2013). A SCARECROWRETINOBLASTOMA Protein Network Controls Protective Quiescence in the Arabidopsis Root Stem Cell Organizer. PLoS Biol. 11, e1001724. 
bioRxiv preprint doi: https://doi.org/10.1101/2022.02.18.481036; this version posted February 19, 2022. The copyright holder for this preprint (which was not certified by peer review) is the author/funder, who has granted bioRxiv a license to display the preprint in perpetuity. It is made available under aCC-BY-NC-ND 4.0 International license.

Della Rovere, F., Fattorini, L., D’Angeli, S., Veloccia, A., Falasca, G. and Altamura, M. M. (2013). Auxin and cytokinin control formation of the quiescent centre in the adventitious root apex of arabidopsis. Ann. Bot. 112, 1395-1407.

Ditengou, F. A., Teale, W. D., Kochersperger, P., Flittner, K. A., Kneuper, I., van der Graaff, E., Nziengui, H., Pinosa, F., Li, X., Nitschke, R., et al. (2008). Mechanical induction of lateral root initiation in Arabidopsis thaliana. Proc. Natl. Acad. Sci. U. S. A. 105, 1881818823.

Dolan, L., Janmaat, K., Willemsen, V., Linstead, P., Poethig, S., Roberts, K. and Scheres, B. (1993). Cellular organisation of the Arabidopsis thaliana root. Development 119, 71-84.

Du, Y. and Scheres, B. (2017). PLETHORA transcription factors orchestrate de novo organ patterning during Arabidopsislateral root outgrowth. Proc. Natl. Acad. Sci. U. S. A. 121, 201714410.

Dubrovsky, J. G. and Ivanov, V. B. (2021). The quiescent centre of the root apical meristem: Conceptual developments from Clowes to modern times. J. Exp. Bot.

Efroni, I., Mello, A., Nawy, T., Ip, P.-L., Rahni, R., DelRose, N., Powers, A., Satija, R. and Birnbaum, K. D. (2016). Root Regeneration Triggers an Embryo-like Sequence Guided by Hormonal Interactions. Cell 165, 1721-1733.

El Arbi, N., Schürholz, A.-K., Schiffner, A., Prados, I. H., Böhme, F., Wenzl, C., Zhao, X., Zeng, J., Lohmann, J. U. and Wolf, S. (2021). ARGONAUTE10 is required for cell fate specification and the control of formative cell divisions in the Arabidopsis root meristem. Cold Spring Harbor Laboratory 2021.02.05.429893.

Fendrych, M., Van Hautegem, T., Van Durme, M., Olvera-Carrillo, Y., Huysmans, M., Karimi, M., Lippens, S., Guérin, C. J., Krebs, M., Schumacher, K., et al. (2014). Programmed Cell Death Controlled by ANAC033/SOMBRERO Determines Root Cap Organ Size in Arabidopsis. Curr. Biol. 24, 931-940.

Fulcher, N. and Sablowski, R. (2009). Hypersensitivity to DNA damage in plant stem cell niches. Proc. Natl. Acad. Sci. U. S. A. 106, 20984-20988.

Goh, T., Toyokura, K., Wells, D. M., Swarup, K., Yamamoto, M., Mimura, T., Weijers, D., Fukaki, H., Laplaze, L., Bennett, M. J., et al. (2016). Quiescent center initiation in the Arabidopsis lateral root primordia is dependent on the SCARECROW transcription factor. Development 143, 3363-3371.

Greb, T. and Lohmann, J. U. (2016). Plant Stem Cells. Curr. Biol. 26, R816-21.

Guyomarc'h, S., Leran, S., Auzon-Cape, M., Perrine-Walker, F., Lucas, M. and Laplaze, L. (2012). Early development and gravitropic response of lateral roots in Arabidopsis thaliana. Philos. Trans. R. Soc. Lond. B Biol. Sci. 367, 1509-1516.

Haecker, A., Gross-Hardt, R., Geiges, B., Sarkar, A., Breuninger, H., Herrmann, M. and Laux, T. (2004). Expression dynamics of WOX genes mark cell fate decisions during early embryonic patterning in Arabidopsis thaliana. Development 131, 657-668.

Jiang, K., Meng, Y. L. and Feldman, L. J. (2003). Quiescent center formation in maize roots is associated with an auxin-regulated oxidizing environment. Development 130, 1429-1438.

Kiss, J. Z., Miller, K. M., Ogden, L. A. and Roth, K. K. (2002). Phototropism and gravitropism in lateral roots of Arabidopsis. Plant Cell Physiol. 43, 35-43. 
Kotogány, E., Dudits, D., Horváth, G. V. and Ayaydin, F. (2010). A rapid and robust assay for detection of S-phase cell cycle progression in plant cells and tissues by using ethynyl deoxyuridine. Plant Methods 6, 5.

Kurihara, D., Mizuta, Y., Sato, Y. and Higashiyama, T. (2015). ClearSee: a rapid optical clearing reagent for whole-plant fluorescence imaging. Development 142, 4168-4179.

Lampropoulos, A., Sutikovic, Z., Wenzl, C., Maegele, I., Lohmann, J. U. and Forner, J. (2013). GreenGate - A Novel, Versatile, and Efficient Cloning System for Plant Transgenesis. PLoS One 8, e83043.

Laskowski, M. J., Williams, M. E., Nusbaum, H. C. and Sussex, I. M. (1995). Formation of lateral root meristems is a two-stage process. Development 121, 3303-3310.

Liao, C.-Y., Smet, W., Brunoud, G., Yoshida, S., Vernoux, T. and Weijers, D. (2015). Reporters for sensitive and quantitative measurement of auxin response. Nat. Methods 12, 207-210.

Lu, R., Canher, B., Bisht, A., Heyman, J. and De Veylder, L. (2021). Three-dimensional quantitative analysis of the Arabidopsis quiescent centre. J. Exp. Bot. 72, 6789-6800.

Lucas, M., Kenobi, K., von Wangenheim, D., VOß, U., Swarup, K., De Smet, I., Van Damme, D., Lawrence, T., Péret, B., Moscardi, E., et al. (2013). Lateral root morphogenesis is dependent on the mechanical properties of the overlaying tissues. Proc. Natl. Acad. Sci. U. S. A. 110, 5229-5234.

Macleod, R. D. (1977). Proliferating and Quiescent Cells in the Apical Meristem of Elongating Lateral Roots of Vicia faba L. Ann. Bot. 41, 321-329.

Maizel, A. and Weigel, D. (2004). Temporally and spatially controlled induction of gene expression in Arabidopsis thaliana. Plant J. 38, 164-171.

Malamy, J. E. and Benfey, P. N. (1997). Organization and cell differentiation in lateral roots of Arabidopsis thaliana. Development 124, 33-44.

Marhavy, P. and Benkova, E. (2015). Real-time Analysis of Lateral Root Organogenesis in Arabidopsis. BIO-PROTOCOL 5,.

Marhavý, P., Duclercq, J., Weller, B., Feraru, E., Bielach, A., Offringa, R., Friml, J., Schwechheimer, C., Murphy, A. and Benková, E. (2014). Cytokinin Controls Polarity of PIN1-Dependent Auxin Transport during Lateral Root Organogenesis. Curr. Biol. 24, 1031-1037.

Montesinos, J. C., Abuzeineh, A., Kopf, A., Juanes-Garcia, A., Ötvös, K., Petrášek, J., Sixt, M. and Benková, E. (2020). Phytohormone cytokinin guides microtubule dynamics during cell progression from proliferative to differentiated stage. EMBO J. 39, e104238.

Motte, H., Vanneste, S. and Beeckman, T. (2019). Molecular and Environmental Regulation of Root Development. Annu. Rev. Plant Biol. 70,.

Müller, B. and Sheen, J. (2008). Cytokinin and auxin interaction in root stem-cell specification during early embryogenesis. Nature 453, 1094-1097.

Nawy, T., Lee, J.-Y., Colinas, J., Wang, J. Y., Thongrod, S. C., Malamy, J. E., Birnbaum, K. and Benfey, P. N. (2005). Transcriptional profile of the Arabidopsis root quiescent center. Plant Cell 17, 1908-1925. 
Nenadić, M. and Vermeer, J. E. M. (2021). Dynamic cytokinin signalling landscapes during lateral root formation in Arabidopsis. Quantitative Plant Biology 2,.

Petersson, S. V., Johansson, A. I., Kowalczyk, M., Makoveychuk, A., Wang, J. Y., Moritz, T., Grebe, M., Benfey, P. N., Sandberg, G. and Ljung, K. (2009). An Auxin Gradient and Maximum in the Arabidopsis Root Apex Shown by High-Resolution Cell-Specific Analysis of IAA Distribution and Synthesis. Plant Cell 21, 1659-1668.

Pi, L., Aichinger, E., van der Graaff, E., Llavata Peris, C. I., Weijers, D., Hennig, L., Groot, E. and Laux, T. (2015). Organizer-Derived WOX5 Signal Maintains Root Columella Stem Cells through Chromatin-Mediated Repression of CDF4 Expression. Dev. Cell 33, 576588.

Radoeva, T., Ten Hove, C. A., Saiga, S. and Weijers, D. (2016). Molecular Characterization of Arabidopsis GAL4/UAS Enhancer Trap Lines Identifies Novel Cell-Type-Specific Promoters. Plant Physiol. 171, 1169-1181.

Rahni, R., Efroni, I. and Birnbaum, K. D. (2016). A Case for Distributed Control of Local Stem Cell Behavior in Plants. Dev. Cell 38, 635-642.

Sabatini, S., Beis, D., Wolkenfelt, H., Murfett, J., Guilfoyle, T., Malamy, J., Benfey, P., Leyser, O., Bechtold, N., Weisbeek, P., et al. (1999). An auxin-dependent distal organizer of pattern and polarity in the Arabidopsis root. Cell 99, 463-472.

Sabatini, S., Heidstra, R., Wildwater, M. and Scheres, B. (2003). SCARECROW is involved in positioning the stem cell niche in the Arabidopsis root meristem. Genes Dev. 17, 354-358.

Salvi, E., Rutten, J. P., Di Mambro, R., Polverari, L., Licursi, V., Negri, R., Dello loio, R., Sabatini, S. and Ten Tusscher, K. (2020). A Self-Organized PLT/Auxin/ARR-B Network Controls the Dynamics of Root Zonation Development in Arabidopsis thaliana. Dev. Cell 53, 431-443.e23.

Scheres, B., Wolkenfelt, H., Willemsen, V., Terlouw, M., Lawson, E., Dean, C. and Weisbeek, P. (1994). Embryonic origin of the Arabidopsis primary root and root meristem initials. Development 120, 2475-2487.

Serrano-Ron, L., Perez-Garcia, P., Sanchez-Corrionero, A., Gude, I., Cabrera, J., Ip, P.-L., Birnbaum, K. D. and Moreno-Risueno, M. A. (2021). Reconstruction of lateral root formation through single-cell RNA sequencing reveals order of tissue initiation. Mol. Plant 14, 1362-1378.

Shimotohno, A., Heidstra, R., Blilou, I. and Scheres, B. (2018). Root stem cell niche organizer specification by molecular convergence of PLETHORA and SCARECROW transcription factor modules. Genes Dev. 32, 1085-1100.

ten Hove, C. A., Willemsen, V., de Vries, W. J., van Dijken, A., Scheres, B. and Heidstra, R. (2010). SCHIZORIZA Encodes a Nuclear Factor Regulating Asymmetry of Stem Cell Divisions in the Arabidopsis Root. Curr. Biol. 20, 452-457.

ten Hove, C. A., Lu, K.-J. and Weijers, D. (2015). Building a plant: cell fate specification in the early Arabidopsis embryo. Development 142, 420-430.

Tian, H., Jia, Y., Niu, T., Yu, Q. and Ding, Z. (2014a). The key players of the primary root growth and development also function in lateral roots in Arabidopsis. Plant Cell Rep. 33, 745-753.

Tian, H., De Smet, I. and Ding, Z. (2014b). Shaping a root system: regulating lateral versus primary root growth. Trends Plant Sci. 19, 426-431. 
Truernit, E., Bauby, H., Dubreucq, B., Grandjean, O., Runions, J., Barthelemy, J. and Palauqui, J. C. (2008). High-Resolution Whole-Mount Imaging of Three-Dimensional Tissue Organization and Gene Expression Enables the Study of Phloem Development and Structure in Arabidopsis. Plant Cell 20, 1494-1503.

Tsugeki, R. and Fedoroff, N. V. (1999). Genetic ablation of root cap cells in Arabidopsis. Proc. Natl. Acad. Sci. U. S. A. 96, 12941-12946.

Ursache, R., Andersen, T. G., Marhavý, P. and Geldner, N. (2018). A protocol for combining fluorescent proteins with histological stains for diverse cell wall components. Plant J. 93, 399-412.

van den Berg, C., Willemsen, V., Hage, W., Weisbeek, P. and Scheres, B. (1995). Cell fate in the Arabidopsis root meristem determined by directional signalling. Nature 378, 62-65.

van den Berg, C., Willemsen, V., Hendriks, G., Weisbeek, P. and Scheres, B. (1997). Shortrange control of cell differentiation in the Arabidopsis root meristem. Nature 390, 287-289.

Vilarrasa-Blasi, J., González-García, M.-P., Frigola, D., Fàbregas, N., Alexiou, K. G., LópezBigas, N., Rivas, S., Jauneau, A., Lohmann, J. U., Benfey, P. N., et al. (2014). Regulation of Plant Stem Cell Quiescence by a Brassinosteroid Signaling Module. Dev. Cell 30, 36-47.

Vilches Barro, A., Stöckle, D., Thellmann, M., Ruiz-Duarte, P., Bald, L., Louveaux, M., von Born, P., Denninger, P., Goh, T., Fukaki, H., et al. (2019). Cytoskeleton Dynamics Are Necessary for Early Events of Lateral Root Initiation in Arabidopsis. Curr. Biol. 29, 24432454.e5.

von Wangenheim, D., Fangerau, J., Schmitz, A., Smith, R. S., Leitte, H., Stelzer, E. H. K. and Maizel, A. (2016). Rules and Self-Organizing Properties of Post-embryonic Plant Organ Cell Division Patterns. Curr. Biol. 26, 439-449.

Waidmann, S., Sarkel, E. and Kleine-Vehn, J. (2020). Same same, but different: growth responses of primary and lateral roots. J. Exp. Bot. eraa027.

Yin, K., Ueda, M., Takagi, H., Kajihara, T., Sugamata Aki, S., Nobusawa, T., Umeda-Hara, C. and Umeda, M. (2014). A dual-color marker system for in vivovisualization of cell cycle progression in Arabidopsis. Plant J. 80, 541-552.

Zürcher, E., Tavor-Deslex, D., Lituiev, D., Enkerli, K., Tarr, P. T. and Müller, B. (2013). A robust and sensitive synthetic sensor to monitor the transcriptional output of the cytokinin signaling network in planta. Plant Physiol. 161, 1066-1075. 
734 Progressive maturation of the root apical meristem in Arabidopsis thaliana lateral roots

736

737 Béatrice Berthet, Lotte Bald, Marion Louveaux and Alexis Maizel

738

739

740 Fig. S1. Expression of WOX5 in early lateral root primordia

741 Fig. S2. Expression of SCR during germination

742 Fig. S3. Apically located cells stop to proliferate post-emergence

743 Fig. S4. EdU incorporation and cell proliferation in LR of wild type and dcr mutant 


\section{LR development}
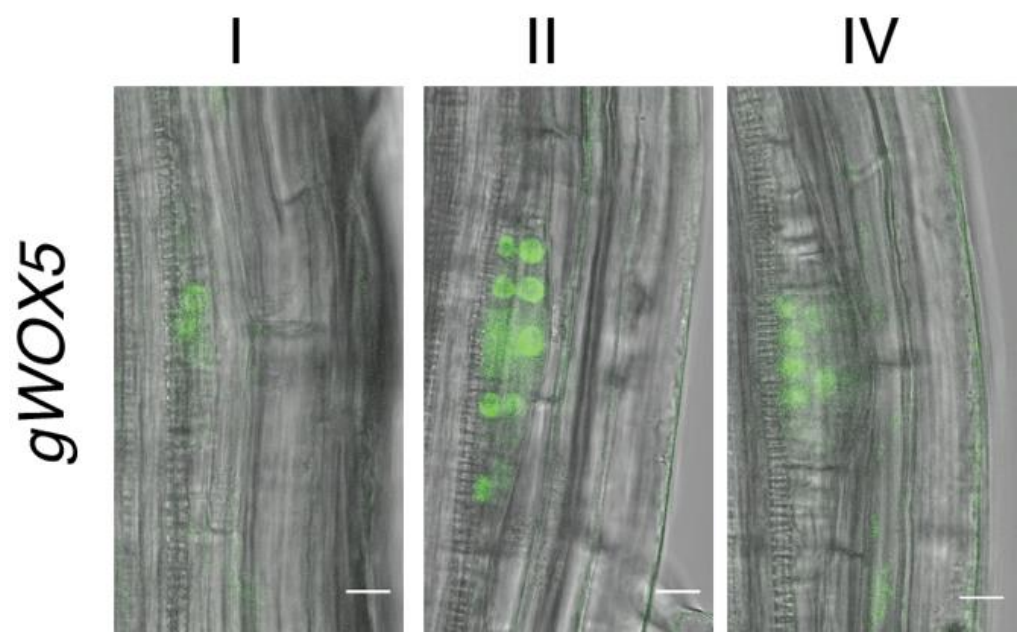

746 Fig. S1 | Expression of WOX5 in early lateral root primordia

747 Confocal section of 10-day-old gWOX5 at stage I, II and IV of lateral root development. Scale bar 10um. 


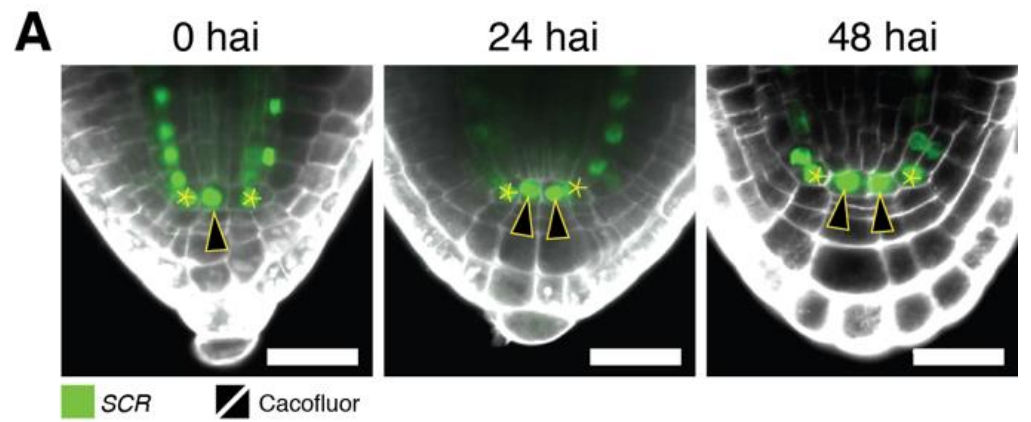

B

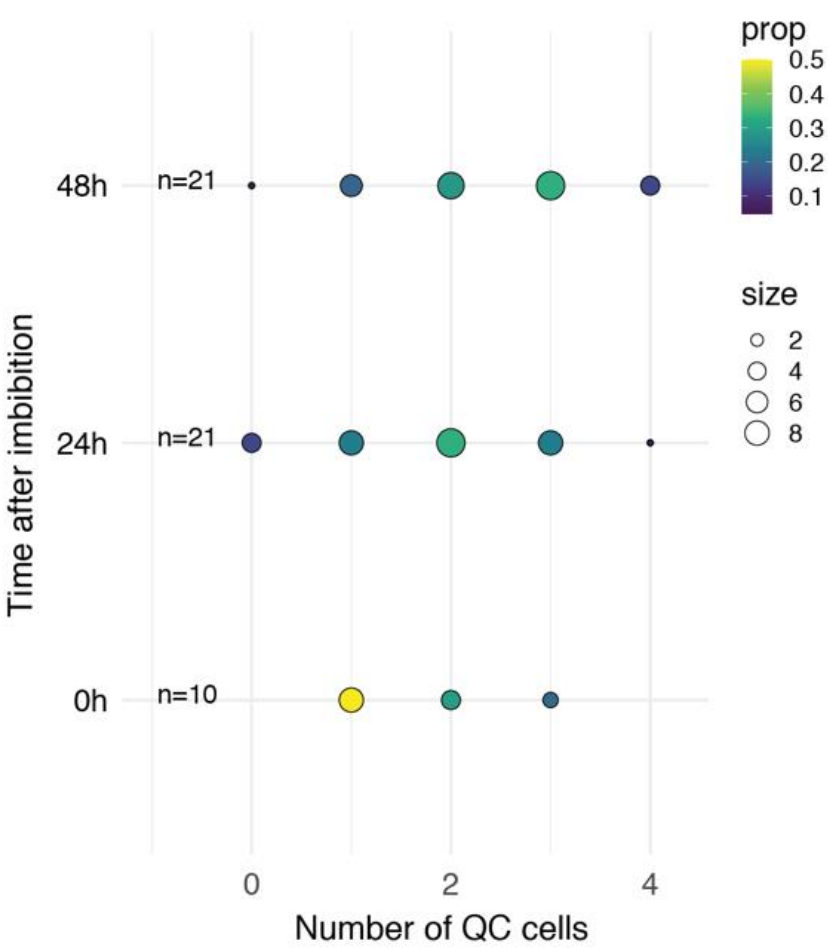

750 Fig. S2 | Expression of SCR during germination

751 (A) Confocal section SCR (pSCR::nGFP) embryos at 0, 24 and 48h post seed imbibition. The QC cells

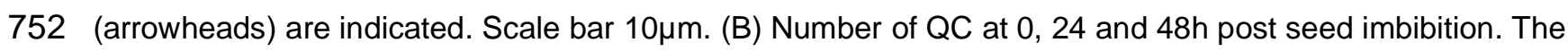
753 size of the circle is proportional to the number of observations (Obs.), and the colour represents the relative 754 proportion of observations within a given class. Total number of observations is indicated. 

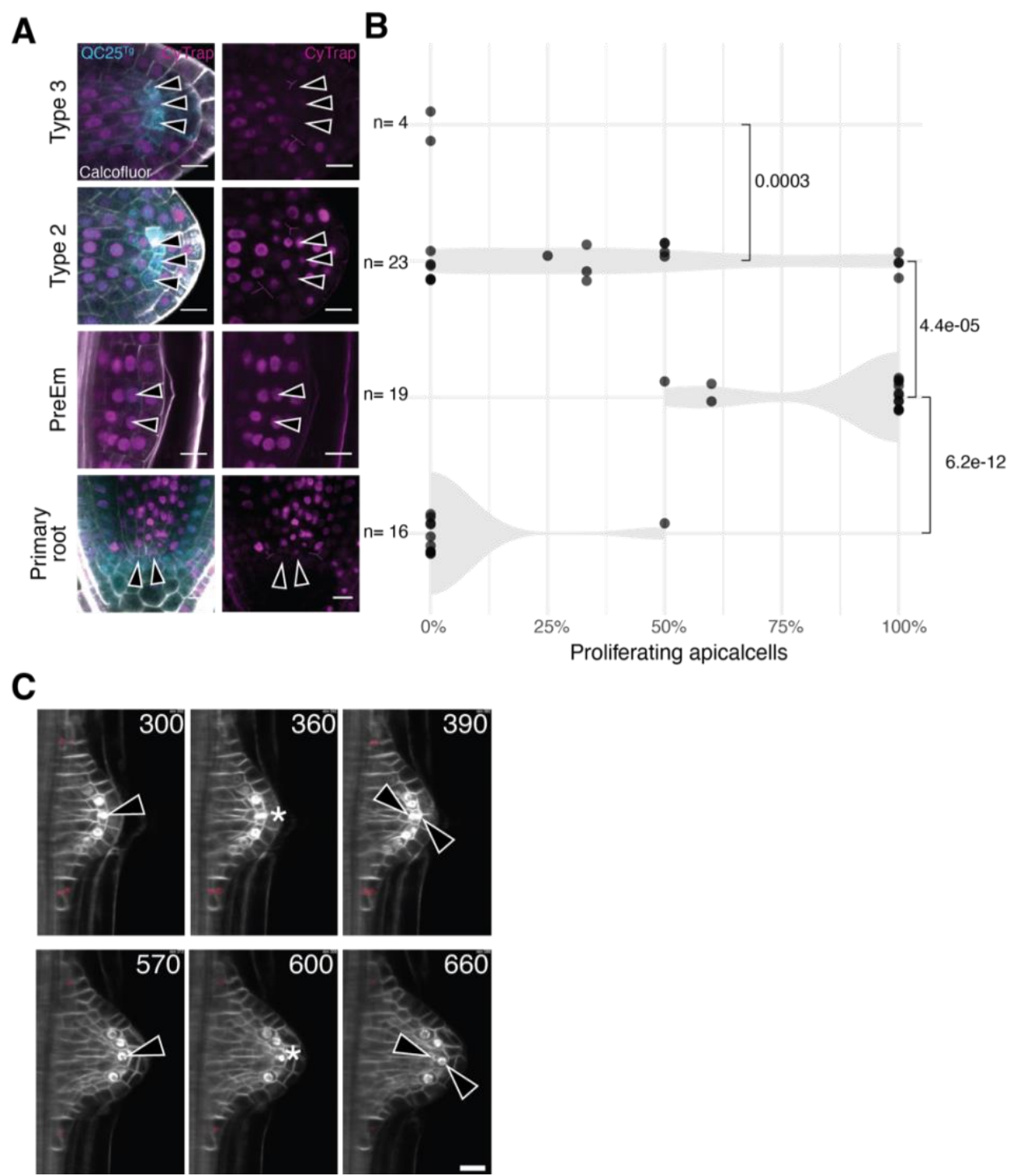

756 Fig. S3 | Apically located cells stop to proliferate post-emergence.

757 (A) Confocal sections of primary root and lateral root apical regions at different stages of development in 758 lines expressing the S-phase marker CyTrap, the apical cell marker QC25 $5^{T g}$ and counterstained with 759 Calcofluor White. Arrowheads indicate the apically located cells. (B) Quantification of the proportion of 760 proliferating apically located cells in the primary root meristem and different stages of LR development. The 761 total number of observations and the statistical significance (Wilcoxon test) of the difference between groups 762 are indicated. (C) Time lapse light sheet imaging of a developing LR expressing SCR (pSCR::nGFP) and a 763 plasma membrane marker (PIP1;4-GFP, see methods). Arrowheads point at apically located cells, while 764 asterisks mark mitosis. Two divisions are observed 360 and 600 minutes after the start of the recording. 765 Scale bars: $10 \mu \mathrm{m}$. 
A

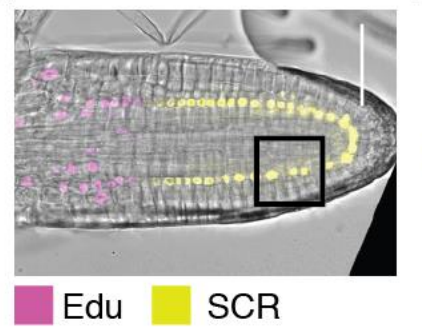

B

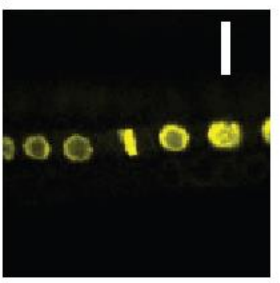

C

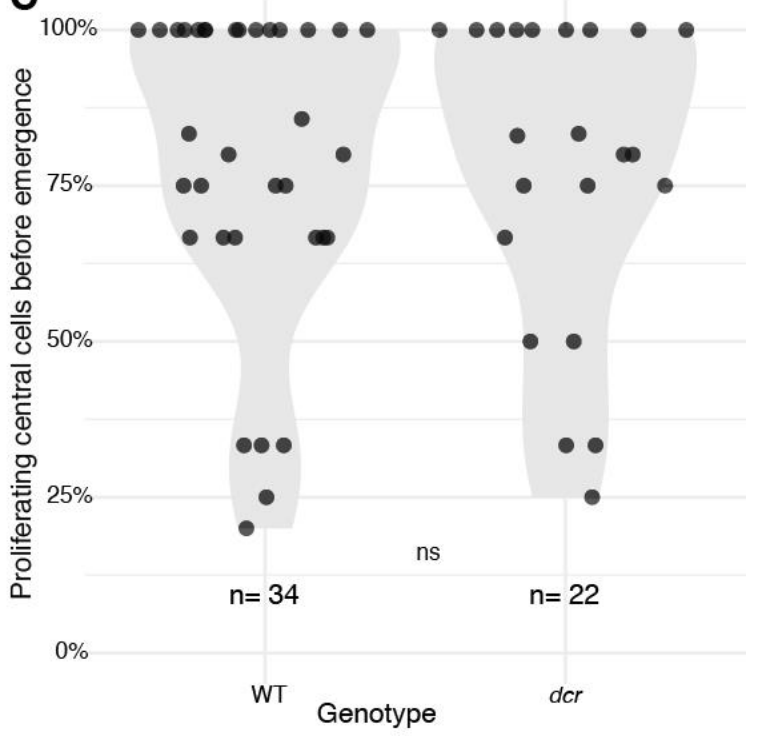

768 Fig. S4 | Lack of EdU incorporation in young wild type emerged lateral roots and comparable 769 proliferation of the lateral roots apically located cells in wild type and $d c r$

770 (A) Confocal section of wild type 10-day-old SCR (pSCR::nGFP) emerged lateral root counterstained with 771 EdU. (B) Close up on the region boxed in (A) showing cell division despite lack of EdU incorporation. (C) 772 Proportion of proliferating apically located cells in stage IV-VI LRP in wild type (WT) and dcr mutant. Each 773 point represents a primordium. The distributions do not differ from each other according to Wilcoxon's test. 